ISSN electrónico: $1885-5210$

DOI: https://doi.org/10.14201/rmc20201612528

\title{
XXY (2007), LA GRAN DECISIÓN DE SER INTERSEXUAL
}

\section{XXY (2007), the big decision of being intersexual}

\section{Mariajose Milagros CARMONA CORCUERA}

Facultad de Medicina Humana. Universidad Privada Norbert Wiener (Perú).

e-mail: majomicarcor99@gmail.com

Fecha de recepción: 7 de junio de 2019

Fecha de aceptación: 2 de septiembre de 2019

Fecha de publicación: 15 de marzo de 2020

\section{Resumen}

En este artículo se centrará en el análisis de la película argentina XXY (2007), de Lucía Puenzo. Es de mi particular interés saber el impacto social y familiar que ocasionaría el velar por un niño «intersex» ya que presenta uno de los mayores desafíos a las estructuras sociales binarias, tal como lo vemos en la película, cuando su condición se vuelve pública.

El objetivo principal de este análisis, es mostrar el estigma las repercusiones psicológicas que el paciente debe atravesar al ser «obligado» a elegir un solo sexo.

Palabras clave: intersexo; impacto social; sexo.

\section{Summary}

In this article, I will focus on the analysis of the Argentine film XXY (2007), by Lucía Puenzo. I'm interested in knowing the social and family impact that would result from having an «intersex» child since it presents one of the greatest challenges to binary social structures, as we see in the film, when its condition becomes public.

The main objective of this analysis is to show the stigma the psychological repercussions that the patient must go through when being "forced" to choose a single sex.

Key words: intersex; social impact; sex.

\section{Ficha técnica}

Título original: $X X Y$.

País: Argentina.

Año: 2007.

Director: Lucía Puenzo.
Música: Andrés Goldstein, Daniel Tarrab.

Fotografía: Natasha Braier.

Montaje: Hugo Primero, Alex Zito.

Guion: Lucía Puenzo (Historia: Sergio Bizzio).

Intérpretes: Inés Efron, Ricardo Darín, Valeria Bertuccelli, Martín Piroyansky, Germán Palacios, Carolina Peleritti, 
Guillermo Angelelli, César Troncoso, Ailín Salas, Lucas Escariz.

Color: color.

Duración: 86 minutos.

Género: drama; adolescencia; familia; homosexualidad.

Idioma: español.

Sinopsis: «Álex (Inés Efron) es una singular adolescente de quince años que esconde un secreto. Poco después de su nacimiento, sus padres, Kraken (Ricardo Darín) y Suli (Valeria Bertuccelli), decidieron dejar Buenos Aires para vivir, aislados del mundo, en una cabaña de madera a orillas del mar. Lo que pretendían era que su hija creciera libre de cualquier tipo de prejuicios, protegida y feliz, hasta que llegara el momento de decidir qué camino debía seguir» (Tomado de Filmaffinity).

Productoras: Wanda Visión S.A., Pyramide Films, Historias Cinematográficas Cinemania, Cinéfondation, Fonds Sud.

Premios: En el año 2007: Festival de Valladolid (Seminci): Nominada a la Espiga de Oro. Premios Goya: Mejor película extranjera de habla hispana.

\section{Enlaces:}

https://www.filmaffinity.com/es/film550411.html https://www.imdb.com/title/tt0995829

\section{Tráiler en español}

La intersexualidad a través de XXY (2007)

"Soy las dos cosas», dijo Alex, «Pero eso no puede ser» respondió Álvaro ${ }^{1}$ (Foto 1).

A partir de este punto se razona: ¿Por qué es necesario elegir, así de taxativo, entre ser hombre o mujer? ¿Por qué para la sociedad es inadmisible vivir con ambos sexos?

Y esto es lo que ocurre con XXY (2007), un film para pensar en la identidad, la hipocresía y el clima social frente a quienes nacen «diferentes». Hay un objetivo claro en esta ópera prima de la argentina Lucía Puenzo, lograr que el espectador piense y decida ${ }^{1}$.

En esta propuesta, el film resulta muy oportuno para abrir el debate entre la libertad de elección versus la «normalización» ${ }^{1}$.

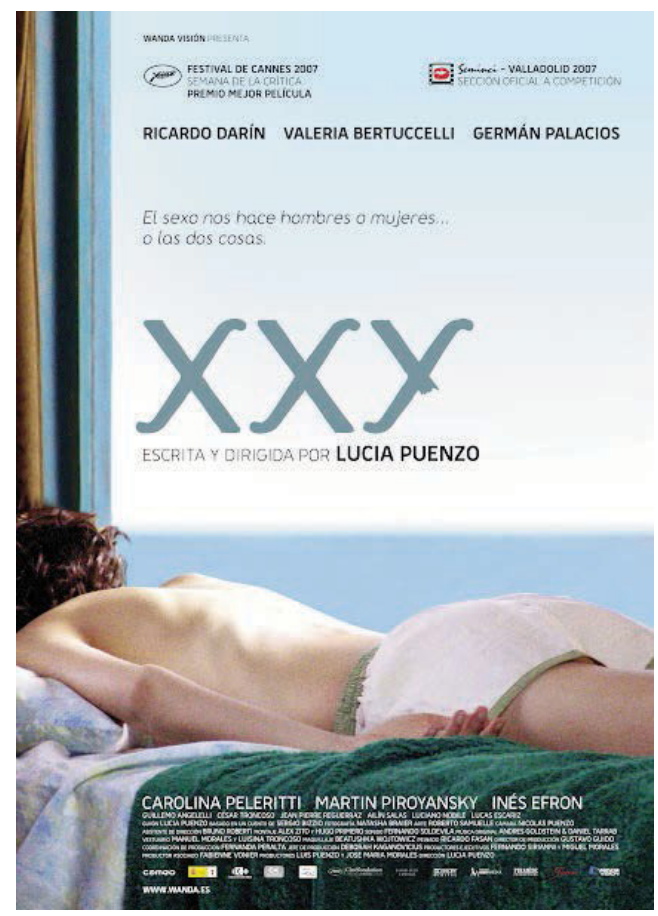

Cartel español.

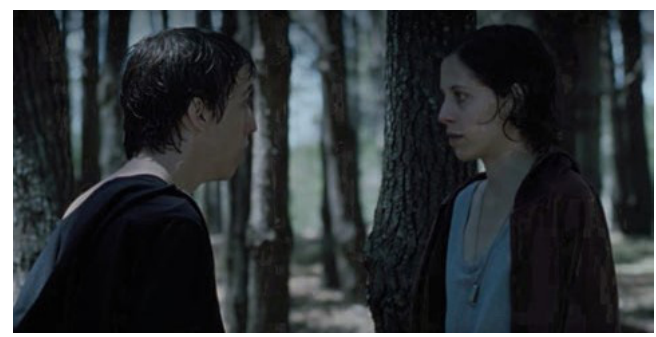

Foto 1. Alex (Inés Efrón) y Álvaro (Martín Piroyansky) teniendo una conversación de lo que realmente sucedió.

Vivimos en una sociedad que lamentablemente está organizada y estructurada según el género. Desde la más temprana infancia, los niños y las niñas son instruidos de que el género es un aspecto central en sus vidas y crecen en un sistema de organización e interacción social que concibe los sexos y los géneros como una dicotomía: la idea de que existen dos sexos y dos géneros, y sólo dos, y que son antitéticos ${ }^{2}$. 
Pero no tenemos en cuenta que en la diferenciación sexual intervienen procesos a nivel genético, hormonal y neurológico, y gracias a ellos puede haber una infinidad de combinaciones, la variedad sexual con la que nos podemos encontrar es prácticamente infinita ${ }^{2}$.

Y precisamente eso es lo que nos muestra XXY (2007), en la cual Alex (Inés Efrón), un adolescente intersexual, debe dejar Argentina junto a su familia para vivir lejos del escrutinio de la gente y así no ser considerado como un "fenómeno»; estando en Uruguay tratan de tener una vida «normal». Pero a los 15 años, Alex decide dejar la medicación y da un paso atrás a la cirugía, con la cual culminaría su proceso de «normalización» (Foto 2).

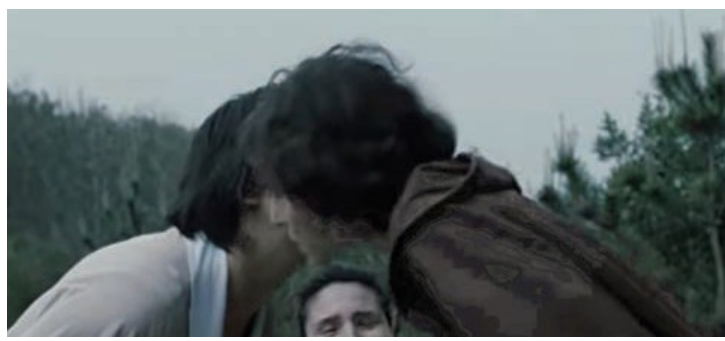

Foto 2. Su mamá Suli (Valeria Bertuccelli) presentando sus amigos a Alex (Inés Efrón).

Por ende, la madre de Alex decidió invitar a una pareja de amigos (Ramiro era cirujano) con su hijo, con el fin que ayudarán a convencer a Alex de que ya era momento de la «normalización». Con lo que no contaron era que entre Álvaro -hijo de la pareja-y Alex se verían envueltos en una relación bastante particular, que irá poco a poco tornándose íntima, hasta el punto de tener relaciones sexuales; donde Alex ocupó el lugar de activo con Álvaro, lo cual resulta revolucionario para ambos, ya que están dando sus primeros pasos en el despertar sexual. A consecuencia de ese acto, Alex se siente en una encrucijada en saber quién es realmente ${ }^{3}$ (Fotos 3 y 4 ).

Las expectativas en torno al sexo y género frecuentemente no son percibidas hasta que alguien distinto a la «norma» aparece, en ese momento son retadas la mayoría de nuestras expectativas sociales dicotómicas, que batallan en creer si lo que están presenciando es posible y sí lo es, tratar que esa persona se «normalice» eligiendo ser entre hombre o mujer².
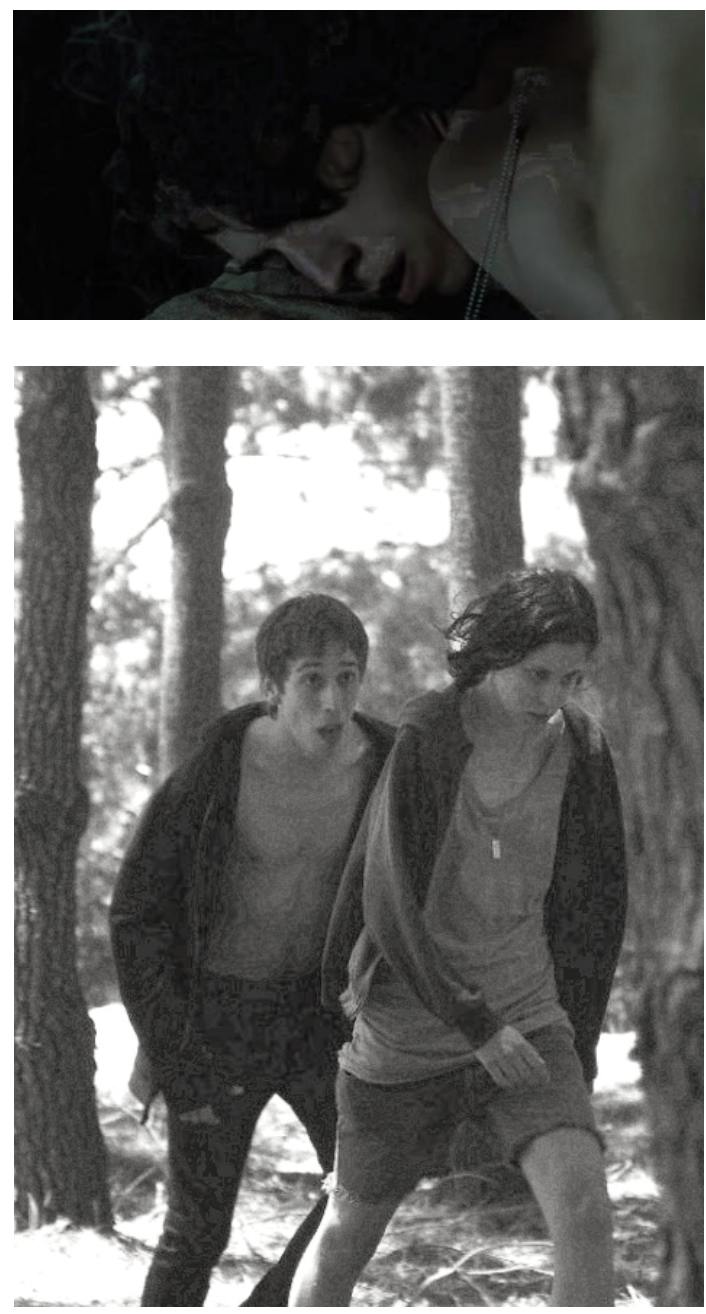

Fotos 3 y 4. Durante y post acto íntimo entre Álvaro (Martín Piroyansky) y Alex (Inés Efrón), respectivamente.

La creencia austera de que existen solamente dos sexos y que está definido por una apariencia genital particular, crea un problema significativo en algunas personas cuyos cuerpos no encajan en esa «normalidad $»^{4}$. Bajo la influencia de esa dicotomía, se va configurando la personalidad y dentro de esta, dos de sus aspectos centrales: identidad y sexualidad ${ }^{2}$.

Sobre esta materia, Goffman afirma que a través de una construcción social emerge la identidad de la 


\section{XXY (2007), LA GRAN DECISIÓN DE SER INTERSEXUAL \\ MARIAJOSE MILAGROS CARMONA CORCUERA}

persona ${ }^{5}$. El estigma es un atributo de la persona, que es desvalorizado por la visión que tenemos de la misma al estar presente ante nosotros.

Lamentablemente, Alex tuvo que pasar por dicha desvaloración, tras percibir un ataque hacia su persona por compañeros de su colegio con el único objetivo de conocer la particularidad de su aparato reproductor; decide de forma tácita no «normalizarse» para cumplir las exigencias ni caprichos de los demás. No seguiría escondiendo quién es en realidad, que sí puede ser «ambos» y que eso está bien (Foto 5).

La normalización deja más tranquilos a los padres y a la sociedad que a los operados, que sufren por dichas intervenciones por solo querer ser tratados como un igual sin que los estén rechazando por su "anormal» sexualidad $^{6}$ (Foto 6).

En este film, el mensaje que nos quiere transmitir es que la libertad de elección es superior a querer ser lo supuestamente "normal»; debemos aceptarla, comprenderla y amarla tal cual es, y no intentar dominarla, ya que sería ilógico tratar de cambiar la gran variedad de sexualidades existentes.

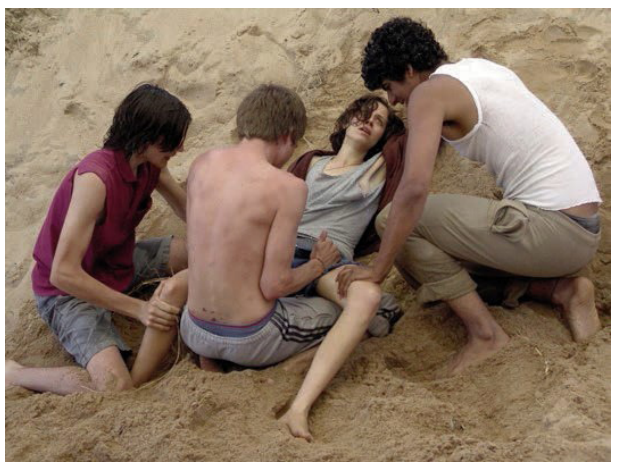

Foto 5. Alex (Inés Efrón) sufre ataque de sus compañeros del colegio.

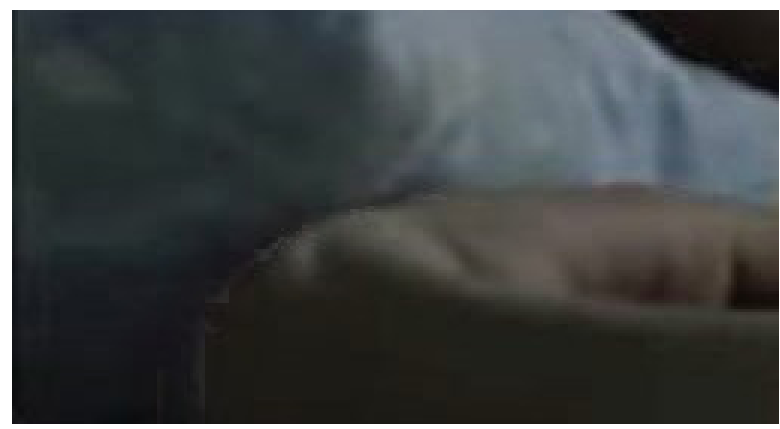

Foto 6. Alex (Inés Efrón) confesando que no hay nada que cambiar.

\section{Referencias}

1. Carbonari P. $X X Y$, algo más que dos sexos [Internet].Cinémas d'Amérique latine. 25 de septiembre de 2015 [consultado 28 de Junio de 2019].

2. Agramonte Machado A. Intersexualidad y estigma social. Revista Sexologia y Sociedad de Cuba. 2008;14(36):18-23.

3. Alvarez Villanueva M. La elección del sexo. Ética y Cine Journal. 2016;6(2):49-52.

4. Vallejo Díaz D. Nociones de prestigio y producción del cuerpo temeroso: Reflexiones en torno a la normalización de cuerpos intersexuales. Sexualidad, Salud y Sociedad - Revista Latinoamericana. 2017;(27):25-45.

5. Goffman E. Estigma. 10a ed. Buenos Aires: Amorrortu; 2010.

6. Piró Biosca C, Audi Parera L, Fernández Cancio M, Martín Osorio JA, Torán Fuentes $\mathrm{N}$, Asensio Llorente $\mathrm{M}$ et al. Diagnóstico y tratamiento quirúrgico del pseudohermafroditismo masculino en una unidad multidisciplinaria de estados intersexuales. Cir Pediatr. 2004;17(2):70-5.

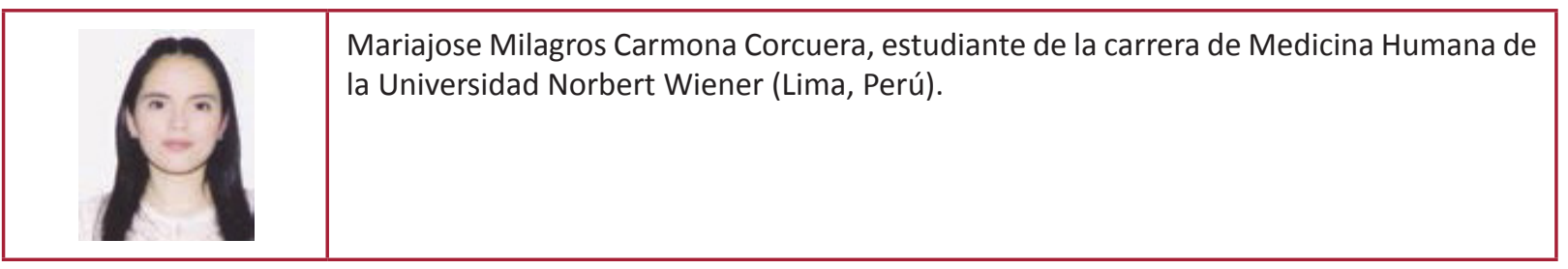

